\title{
The thermal and mechanical performance of cement-based composites with enhanced thermal insulation properties
}

\author{
Z. Pavlík, M. Záleská, M. Pavlíková \& R. Černý \\ Department of Materials Engineering and Chemistry, \\ Faculty of Civil Engineering, Czech Technical University in Prague, \\ Czech Republic
}

\begin{abstract}
Cement-based composites are characterized by their good mechanical properties but they often lack a thermal insulation capability. In this paper, crushed waste polypropylene (PP) originating from PP tubes production is applied for the preparation of composites with enhanced thermal insulation properties which can be used for a reduction of heat transfer in contemporary buildings. In the composite design, the natural aggregate is substituted with the plastic waste in amounts of $10,20,30,40$, and $60 \%$ by mass. A reference mixture without plastic addition is studied as well, for the sake of comparison. For the researched PP granular aggregate, thermal conductivity, thermal diffusivity and volumetric heat capacity are measured in dependence on powder density and material compacting using an impulse technique. In this way, the possibility of improvement of thermal insulation properties of cement-based composites is accessed. The assessment of heat transport and storage properties of plastic waste represents new information for the proper design and development of lightweight composites suitable for the improvement of the thermal stability of buildings. For the developed composites, basic physical, mechanical, and heat transport and storage properties are measured. The thermal transmittance and thermal resistance are then calculated, assuming a typical arrangement of a building floor structure. The application of PP results in an improvement of thermal insulation properties with an acceptable decrease of mechanical resistivity. This gives a good prerequisite for further investigations of composite materials with enhanced thermal insulation function.
\end{abstract}

Keywords: recycled plastic aggregate, cement-based composite, heat transport, thermal resistance, thermal transmittance. 


\section{Introduction}

The energy performance of a building is becoming increasingly important, because of environmental restrictions and rising costs of fuel and energy. The building sector accounted for $25 \%$ of the total final energy consumption in the world in 2010 [1], the third largest after industry (32\%) and transportation (31\%). Although the buildings share of the world total energy consumption is expected to decrease due to the longtime enhanced demands on quality thermal insulation of buildings that led to the design and development of low energy and passive houses [2], buildings will still account for $20 \%$ of the total energy demand in coming years. Moreover, the energy consumption of ventilation and air conditioning is today still increasing because of the increasing demand on thermal comfort of buildings [3]. For the improvement of energy efficiency of buildings, there is necessary to focus on advanced technical solution of building design resulting in building envelopes with high thermal resistance and sufficient thermal stability. Specific attention must be paid not only to the design of building envelopes, but also to the thermal insulation of buildings subsoil. Here, new materials improving the thermal insulation properties of concrete can find use.

In the last decades, due to the increasing cost of raw materials and the continuous reduction of natural resources, the recycling of industrial waste or by-products has become an interesting option for the building industry. Fly ash, demolition waste, bottom ash from municipal solid waste incineration, silica fume, ground granulated blast furnace slag can be considered common materials in the construction industry now. Concrete is beyond question the most important building material. Its worldwide annual production is presently more than 10 billion tons [4], and one can expect rapid increase of its manufacturing in the near future especially in the developing countries whose economies rapidly grow. Instead of the concrete excellent mechanical and durability properties that are the main reasons for its usage, its production brings several harmful secondary effects to the human society and environment. Except high amount of $\mathrm{CO}_{2}$ emission released within the clinker productions, there is the vast amount of natural resources needed to produce such high amount of building material each year. On this account, taking into account the sustainability principles, there is necessary to take advantage of secondary-raw materials coming from industry for concrete production. Application of any industrial waste or/and by-product for concrete manufacturing represents a tremendous saving of energy and has important environmental benefits.

A substantial growth in the consumption of plastic is observed all over the world in recent years, which has led to huge quantities of plastic-related waste [5]. Annual consumption of plastics in Western Europe is about 60 million tons, which results in about 23 million tons of plastics waste. The EU Packing and Packaging Waste Directive (2004/12/CE) had the objective to reclaim or incinerate (using energy recovery) at least $60 \mathrm{wt} \%$ of packaging waste and to recycle between $55 \mathrm{wt} \%$ and $85 \mathrm{wt} \%$ of it [6]. The use of this type of waste in the construction field may represent an effective solution both to the problem of 
reducing the environmental impact of plastics and to the development of an increasingly sustainable building industry. On this account, recycling of plastic waste to produce new materials like concrete or mortar appears as one of the best solution for disposing of plastic waste, due to its economic and ecological advantages. A review on the use of plastic waste in preparation of cement mortar and concrete preparation is already available [7]. However, several important properties such as pore size distribution, thermophysical properties, durability performance of cement mortar and concrete containing plastic as aggregate were not discussed before due to lack of available information. Data were provided only for some of properties, where plastic was used as fibre in concrete and therefore the amount incorporated was very low in comparison to its use as aggregate or filler [5]. On this account, the possibility of recycling crushed waste PP coming from PP tubes production as lightweight aggregate instead of sand in the manufacturing of the cement-based composites with improved thermal insulation properties is researched in the paper. This material should find application as light-weight concrete for spread layer of floor structure, whereas the developed material will be used as dry mixture of binder, plastic and sand, and will be produced on building site. The main aim of the presented research is to optimise the plastic waste addition in terms of physical, mechanical and thermal performance of the resulting cement-based composite.

\section{Experimental}

\subsection{Studied materials}

Within the experimental testing, basic physical and thermal properties of crushed waste PP coming from PP tubes production were accessed at first. The PP waste was then used as partial natural aggregate replacement in cement-based composite mix design. The sized silica sand was mixed from three types of sand in ratio 1:1:1 and was delivered by Heidelberg Cement Group, Brněnské písky Ltd., affiliated company Bratčice, Czech Republic. The grain size curve of the applied sand is given in Figure 1. The natural aggregate was substituted with the plastic waste at weight dosages of $10,20,30,40$, and $50 \%$, whereas the reference mixture without plastic addition was studied as well. The composites were prepared with Portland cement CEM I 42.5 R. Composition of tested composites is given in Table 1.

Table 1: Composition of researched composites.

\begin{tabular}{|c|c|c|c|c|c|c|}
\hline \multicolumn{2}{|c|}{ Material } & $\mathrm{C}_{\text {ref }}$ & $\mathrm{C} 10$ & $\mathrm{C} 20$ & $\mathrm{C} 30$ & $\mathrm{C} 50$ \\
\hline Portland cement CEM 42.5 R & $\mathrm{g}$ & 450 & 450 & 450 & 450 & 450 \\
\hline PP waste & $\mathrm{g}$ & - & 135 & 270 & 405 & 675 \\
\hline Natural aggregate - I, II, III type & $\mathrm{g}$ & 1350 & 1215 & 1080 & 945 & 675 \\
\hline Water & $\mathrm{ml}$ & 280 & 280 & 225 & 225 & 180 \\
\hline Water/cement ratio & - & 0.6 & 0.6 & 0.5 & 0.5 & 0.4 \\
\hline
\end{tabular}




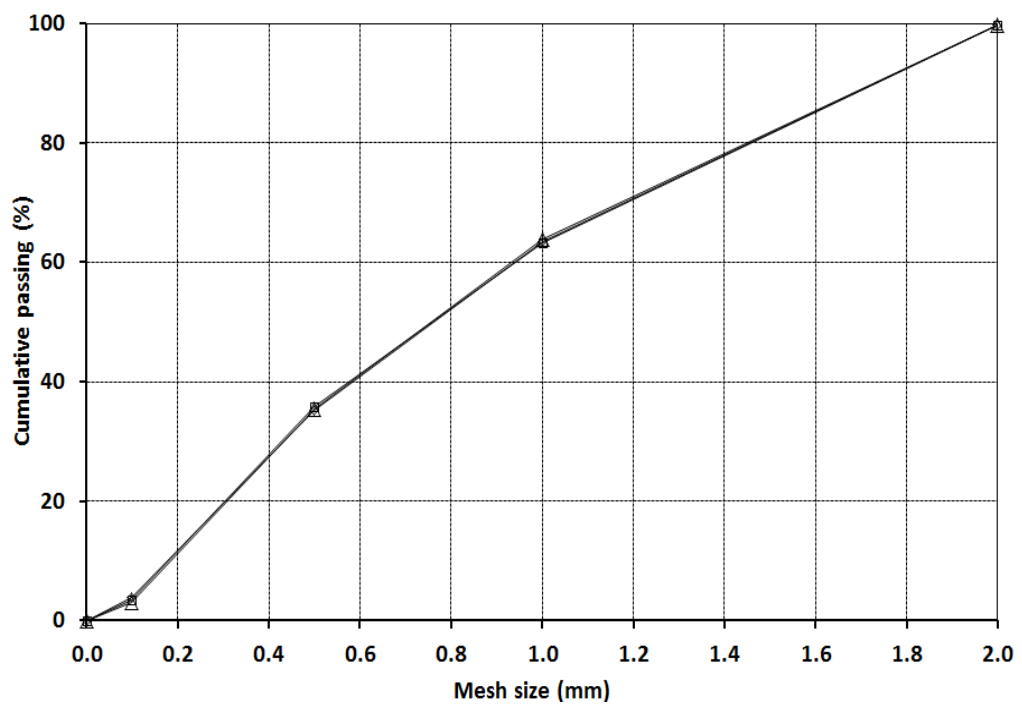

Figure 1: Grain-size curve of used mixed sand.

\subsection{Basic material properties of PP aggregate}

For the PP waste, the measurement of grain-size curve, powder density, matrix density, and pores size distribution was done. The grain size analysis was realized using standard sieve method using sieves of the following mesh dimensions: $0.063 ; 0.125 ; 0.25 ; 0.5 ; 1.0 ; 2.0 ; 4.0 ; 8.0 ; 16.0 ; 31.5$; and $63.0 \mathrm{~mm}$. Results of grain-size sieve analysis are given in Figure 2.

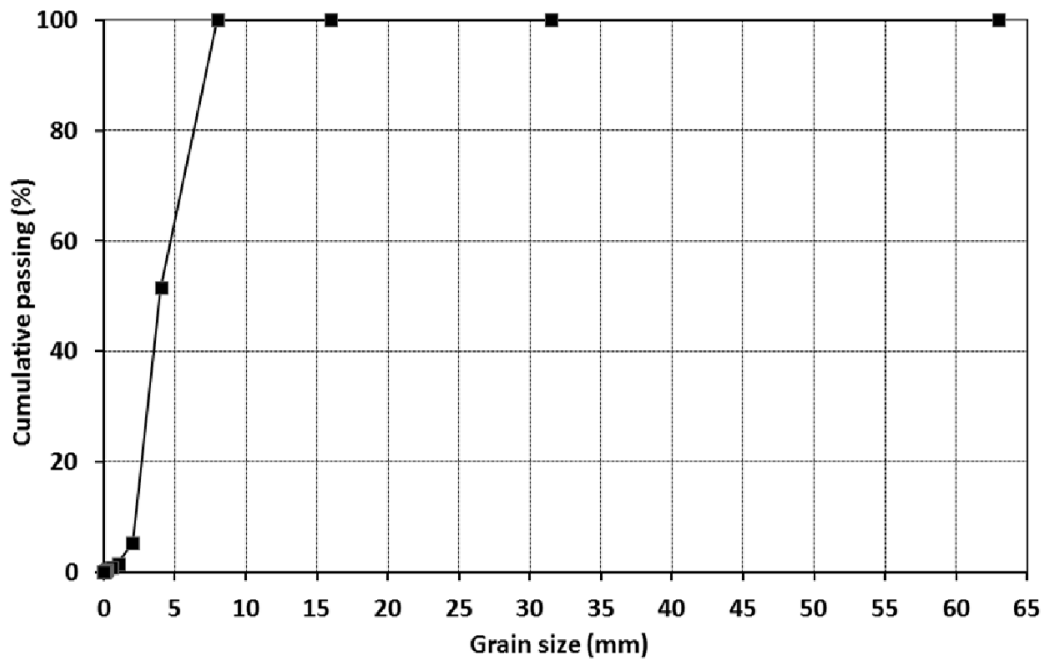

Figure 2: Grain-size curve of PP waste. 
We can see that $100 \%$ of particles were smaller than $8 \mathrm{~mm}$ what is beneficial for incorporation into the composition of the light-weight composites.

Powder density was measured in dependence on compacting time. During the measurement, the PP waste was put into the graduated cylinder and compacted using the vibration exciter. From the know mass of the sample in cylinder and its volume, powder density was evaluated. Matrix density was measured by helium pycnometry using apparatus Pycnomatic ATC (Thermo Scientific). Within application of Pycnomatic ATC, a well dried sample of studied material is weighed and placed in a calibrated reference chamber of known volume. Helium is first loaded at known pressure in a calibrated reference chamber and then expanded into the sample chamber. Once the pressure is stabilized, experimental data are collected and the material volume is accessed. The accuracy of the gas volume measurement using this device is $\pm 0.01 \%$ from the measured value, whereas the accuracy of used analytical balances is $\pm 0.0001 \mathrm{~g}$.

\subsection{Basic physical properties of composite}

Among the basic material properties, bulk density, matrix density and total open porosity were determined. Bulk density was accessed on the gravimetric principle from measured sample size using digital length meter and its dry mass. For this measurement, 5 cubic samples of side $100 \mathrm{~mm}$ were used. The matrix density was determined also on helium pycnometry principle. On the basis of bulk density and matrix density measurements, the total open porosity was calculated [8]. The relative expanded uncertainty of applied testing method was $5 \%$.

\subsection{Mechanical properties}

Mechanical resistivity of researched composites was characterized by compressive strength, bending strength and Young's modulus. The measurements were done on samples cured 28 days in water. The bending strength of cured composites was determined on prismatic samples having dimensions $40 \times 40 \times 160 \mathrm{~mm}$ using the procedure described in CSN EN 12390-5. The compressive strength was measured according to the ČSN EN 12390-3 on fragments of samples from bending strength testing [9]. The loading area was 40 x $40 \mathrm{~mm}$. Young's modulus was measured on dynamic principle using the pulse ultrasonic method. In the experiments, the samples were prisms having dimensions of $40 \times 40 \times 160 \mathrm{~mm}$, and the measurements were performed in longitudinal direction. The ultrasonic pulse method is based on the measurement of travel time of ultrasonic wave launched from the device and passing through the material. For the measurement we used device DIO 562 working on the frequency of $50 \mathrm{KHz}$.

\subsection{Thermal properties}

In order to evaluate the effect of plastic aggregate application on improvement of thermal insulation properties, thermal conductivity $\lambda(\mathrm{WmK})$, thermal diffusivity 
a $\left(\mathrm{m}^{2} / \mathrm{s}\right)$ and volumetric heat capacity $\mathrm{C}_{\mathrm{v}}\left(\mathrm{J} / \mathrm{m}^{3} \mathrm{~K}\right)$ were measured. Together with thermal properties of researched composites, heat transport and storage properties were measured also for plastic aggregate. Here, the measurements were performed in dependence on powder density.

For our measurements, the commercially produced device ISOMET 2114 (Applied Precision, Ltd.) was used as a representative of transient impulse methods. The measuring device applies a dynamic measurement method which enables to reduce the period of thermal conductivity measurements to approximately 10-15 minutes [11]. The measurement is based on analysis of the temperature response of the analysed material to heat flow impulses. The heat flow is induced by electrical heating using a resistor heater having a direct thermal contact with the surface of the sample. The reproducibility of ISOMET 2114 for thermal conductivity measurement is $3 \%$ of reading $+0.001 \mathrm{~W} / \mathrm{mK}$ and for volumetric heat capacity $3 \%$ of reading $+1 \cdot 10^{3} \mathrm{~J} / \mathrm{m}^{3} \mathrm{~K}$. The measurement accuracy is given in the following table.

Table 2: Measurement accuracy of ISOMET 2114.

\begin{tabular}{|c|c|c|}
\hline Measurement & Measurement range & Accuracy \\
\hline Thermal conductivity & $0.015-0.70 \mathrm{~W} / \mathrm{mK}$ & $\begin{array}{c}5 \% \text { of reading }+0.001 \\
\text { W/mK }\end{array}$ \\
\cline { 2 - 3 } & $0.7-6.0 \mathrm{~W} / \mathrm{mK}$ & $10 \%$ of reading \\
\hline $\begin{array}{c}\text { Volumetric heat } \\
\text { capacity }\end{array}$ & $4.0 \cdot 10^{4}-4.0 \cdot 10^{6} \mathrm{~J} / \mathrm{m}^{3} \mathrm{~K}$ & $\begin{array}{c}15 \% \text { of reading }+1.103 \\
\mathrm{~J} / \mathrm{m}^{3} \mathrm{~K}\end{array}$ \\
\hline Temperature & $-20+70^{\circ} \mathrm{C}$ & $1{ }^{\circ} \mathrm{C}$ \\
\hline
\end{tabular}

The measurements were done on dry materials. The composite samples (cubic, with a side dimension of $70 \mathrm{~mm}$ ) were measured using surface probe. For the measurement of PP aggregates, needle probe was used. Here, the measurements were realized in a graduated cylinder in dependence on compacting time having a relation to material powder density.

For the tested materials, thermal transmittance (U-Value) and thermal resistance (R-Value) were calculated assuming the thickness of composites layer $0.1 \mathrm{~m}$. Thermal resistance of composite layer was calculated using Eq. (1)

$$
R=\frac{d}{\lambda_{\text {eff }}},
$$

where $R\left(\mathrm{~m}^{2} \mathrm{~K} / \mathrm{W}\right)$ is thermal resistance, $d(\mathrm{~m})$ material thickness and $\lambda_{\text {eff }}$ $(\mathrm{W} / \mathrm{mK})$ measured effective thermal conductivity of studied material. Thermal resistance of the whole structure is expressed as

$$
R_{T}=R_{s i}+R+R_{s e},
$$

where $R_{T}\left(\mathrm{~m}^{2} \mathrm{~K} / \mathrm{W}\right)$ is total thermal resistance of structures within the heat transfer, $R_{s i}\left(\mathrm{~m}^{2} \mathrm{~K} / \mathrm{W}\right)$ thermal resistance for the heat transfer at interior surface (for floor structure $0.17 \mathrm{~m}^{2} \mathrm{~K} / \mathrm{W}$ ) and $R_{s e}\left(\mathrm{~m}^{2} \mathrm{~K} / \mathrm{W}\right.$ ) thermal resistance for the heat 
transfer at exterior surface (for winter period $0.04 \mathrm{~m}^{2} \mathrm{~K} / \mathrm{W}$ ). Thermal transmittance $U\left(\mathrm{~W} / \mathrm{m}^{2} \mathrm{~K}\right)$ was calculated from Eq. (3)

$$
U=\frac{1}{R_{T}} .
$$

\section{Results and discussion}

Basic physical properties of tested materials are summarized in Table 3. With increasing amount of applied PP aggregate the material porosity systematically increases. This effect is highly positive from the point of view of better thermal insulation properties of the developed composites. The plastic modified composites can be classified as lightweight concrete (according to the standard ČSN EN 206-1), since their bulk densities reach values at the interval 800-2000 $\mathrm{kg} / \mathrm{m}^{3}$.

Table 3: Composition of researched composites.

\begin{tabular}{|c|c|c|c|}
\hline Material & $\begin{array}{c}\text { Bulk density } \\
\left(\mathrm{kg} / \mathrm{m}^{3}\right)\end{array}$ & $\begin{array}{c}\text { Matrix density } \\
\left(\mathrm{kg} / \mathrm{m}^{3}\right)\end{array}$ & $\begin{array}{c}\text { Total open } \\
\text { porosity } \\
\left(\% \mathrm{~m}^{3} / \mathrm{m}^{3}\right)\end{array}$ \\
\hline Cref & 2064 & 3121 & 33.9 \\
\hline C10 & 1798 & 2779 & 35.3 \\
\hline C20 & 1620 & 2554 & 36.6 \\
\hline C30 & 1358 & 2384 & 43.0 \\
\hline C50 & 953 & 2060 & 53.8 \\
\hline PP aggregate & - & 905 & - \\
\hline
\end{tabular}

Mechanical properties are presented in Table 4. The high porosity of composites with incorporated plastic aggregate led in comparison with the reference mixture to a decrease of mechanical resistivity (Figure 3). However, the plastic modified composites exhibited sufficient mechanical strength for their application in multi-layered structure of floor. Compared to the standard thermal insulation material as mineral wool, composite material with $50 \%$ replacement of natural aggregate by PP gives compressive strength approximately 10 times higher.

Table 4: Mechanical properties of tested composites.

\begin{tabular}{|c|c|c|c|}
\hline Material & $\begin{array}{c}\text { Compressive strength } \\
(\mathrm{MPa})\end{array}$ & $\begin{array}{c}\text { Bending strength } \\
(\mathrm{MPa})\end{array}$ & $\begin{array}{c}\text { Young's modulus } \\
(\mathrm{GPa})\end{array}$ \\
\hline Cref & 40.2 & 8.2 & 24.1 \\
\hline C10 & 30.4 & 6.4 & 4.3 \\
\hline C20 & 24.4 & 5.2 & 3.2 \\
\hline C30 & 13.3 & 3.1 & 2.3 \\
\hline C50 & 3.4 & 1.4 & 1.6 \\
\hline
\end{tabular}


Looking at data presented in Figure 3, one can see exponential dependence of compressive and bending strength of researched materials on their porosity. Usually, the cement based composites exhibit linear dependence of their mechanical properties on porosity but also exponential models were formulated for description of this materials performance. The obtained results we put down to the effect of plastic aggregate that within the mechanical loading shows certain compressibility contrary to the mechanical performance of cement hydration products.

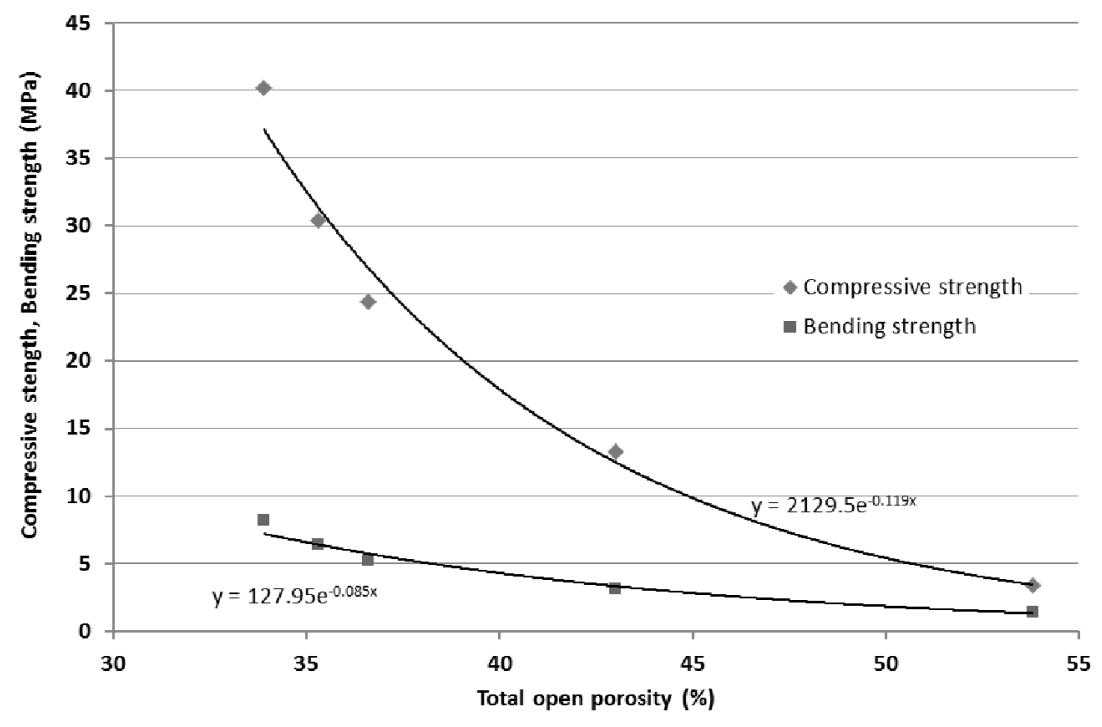

Figure 3: Dependence of mechanical properties on porosity.

Thermal properties of PP aggregate and developed composites are given Tables 5, 6. One can see that with increasing powder density, thermal conductivity of PP waste aggregate increased, as well as its volumetric heat capacity. However, the differences in thermal conductivity values were very small, typically in the range of measuring error. On the other hand, with longer time of compaction, decline in thermal diffusivity values was measured. The data measured for tested composites revealed the positive effect of PP aggregate incorporation on the moderation of heat transport. The increasing amount of PP aggregate in composites composition led to a substantial decrease of thermal conductivity. For example, $50 \%$ replacement of natural aggregate gave thermal conductivity that was about $85 \%$ lower, as compared to the reference material. This finding is highly promising for an application of the developed composite in thermal insulation layers of floor structures. For this PP highly modified material, the promising thermo-technical parameters were also calculated. Assuming the thickness of material C50 $0.1 \mathrm{~m}$, one third of required thermal resistance value for the floor structure in contact with subsoil was reached. 
Table 5: Thermal properties of PP aggregate.

\begin{tabular}{|c|c|c|c|c|c|}
\hline $\begin{array}{c}\text { Compaction } \\
\text { time } \\
(\mathrm{s})\end{array}$ & $\begin{array}{c}\text { Volume after } \\
\text { compaction }(\mathrm{ml})\end{array}$ & $\begin{array}{c}\text { Powder } \\
\text { density } \\
\left(\mathrm{g} / \mathrm{cm}^{3}\right)\end{array}$ & $\begin{array}{c}\lambda \\
(\mathrm{W} / \mathrm{mK})\end{array}$ & $\begin{array}{c}\mathrm{C}_{\mathrm{v}} \\
\left(10^{6}\right. \\
\left.\mathrm{J} / \mathrm{m}^{3} \mathrm{~K}\right)\end{array}$ & $\begin{array}{c}\mathrm{a} \\
\left(10^{-6}\right. \\
\left.\mathrm{m}^{2} / \mathrm{s}\right)\end{array}$ \\
\hline 0 & 980 & 0.382 & 0.098 & 0.240 & 0.408 \\
\hline 10 & 880 & 0.425 & 0.098 & 0.272 & 0.358 \\
\hline 20 & 860 & 0.435 & 0.098 & 0.279 & 0.351 \\
\hline 30 & 840 & 0.445 & 0.100 & 0.258 & 0.389 \\
\hline 60 & 840 & 0.445 & 0.100 & 0.258 & 0.389 \\
\hline 90 & 830 & 0.451 & 0.101 & 0.296 & 0.337 \\
\hline 120 & 820 & 0.456 & 0.102 & 0.297 & 0.336 \\
\hline 180 & 820 & 0.456 & 0.105 & 0.299 & 0.336 \\
\hline 240 & 800 & 0.467 & 0.108 & 0.322 & 0.310 \\
\hline
\end{tabular}

Table 6: Thermal properties of composites.

\begin{tabular}{|c|c|c|c|c|c|}
\hline Material & $\begin{array}{c}\lambda \\
(\mathrm{W} / \mathrm{m} . \mathrm{K})\end{array}$ & $\begin{array}{c}\mathrm{C}_{\mathrm{v}} \\
\left(10^{6} \mathrm{~J} / \mathrm{m}^{3} \mathrm{~K}\right)\end{array}$ & $\begin{array}{c}\mathrm{a} \\
\left(10^{-6} \mathrm{~m}^{2} / \mathrm{s}\right)\end{array}$ & $\begin{array}{c}\mathrm{U} \\
\left(\mathrm{W} / \mathrm{m}^{2} \mathrm{~K}\right)\end{array}$ & $\begin{array}{c}\mathrm{R} \\
\left(\mathrm{m}^{2} \mathrm{~K} / \mathrm{W}\right)\end{array}$ \\
\hline Cref & 1.614 & 1.745 & 1.128 & 16.129 & 0.062 \\
\hline $\mathrm{C} 10$ & 1.451 & 1.671 & 0.831 & 14.493 & 0.069 \\
\hline $\mathrm{C} 20$ & 1.096 & 1.458 & 0.656 & 10.990 & 0.091 \\
\hline $\mathrm{C} 30$ & 0.649 & 1.431 & 0.445 & 6.494 & 0.154 \\
\hline $\mathrm{C} 50$ & 0.233 & 0.421 & 0.553 & 2.331 & 0.429 \\
\hline
\end{tabular}

\section{Conclusions}

Experimental results presented in this paper provided information on the thermal and mechanical performance of the developed composites with incorporated PP aggregate. The assessment of thermal transport and storage properties of plastic waste represents novel information for the design and development of lightweight composites aimed at the improvement the thermal stability of buildings. The application of PP results in an improvement of thermal insulation properties with acceptable decrease of mechanical resistivity. The obtained results present good fundamentals for further studies aimed at an advanced design of composite materials with enhanced thermal insulation function.

\section{Acknowledgements}

This research has been supported by the Czech Science Foundation, under project No. P105/12/G059. The authors are also grateful to the company FV Plast, a.s., Czech Republic that provided the PP waste. 


\section{References}

[1] Pavlík, Z., Černý, R., Hygrothermal Performance Study of an Innovative Interior Thermal Insulation System. Applied Thermal Engineering, 29(10), pp. 1941-1946, 2009.

[2] Tatsidjodoung, P., Le Pierrès, N., Luo, L., A review of potential materials for thermal energy storage in building applications. Renewable and Sustainable Energy Reviews, 18, pp. 327-349, 2013.

[3] Pavlík, Z., Trník, A., Keppert, M., Pavlíková, M., Žumár, J., Černý, R., Experimental Investigation of the Properties of Lime-Based PlasterContaining PCM for Enhancing the Heat-Storage Capacity of Building Envelopes. International Journal of Thermophysics, doi: 10.1007/s10765013-1550-8, 2013.

[4] Meyer, C., The greening of the concrete industry. Cement and Concrete Composites, 31, pp. 601-605, 2009. no. 9.

[5] Saikia, N. \& Jorge de Brito, J., Use of plastic waste as aggregate in cement mortar and concrete preparation: A review. Construction and Building Materials, 34, pp. 385-401, 2012.

[6] Iucolano F., B. Liguori, B., Caputo, D., Colangelo, Cioffi, R., Recycled plastic aggregate in mortars composition: Effect on physical and mechanical properties. Materials and Design, 52, pp. 916-922, 2013.

[7] Siddique R., Khatib J., Kaur I. Use of recycled plastic in concrete: a review. Waste Management, 28, pp. 1835-52, 2008.

[8] Pavlíková, M., Pavlík, Z., Keppert, M., Černý, R., Salt transport and storage parameters of renovation plasters and their possible effects on restored buildings' walls. Construction and Building Materials, 25(3), pp. 1205-1212, 2011.

[9] Keppert, M., Reiterman, P., Pavlík, Z., Pavlíková, M., Jerman, M., Černý, R., Municipal solid waste incineration ashes and their potential for partial replacement of Portland cement and fine aggregates in concrete. Cement Wapno Beton, 15/77(4), pp. 187-193, 2010.

[10] Jiřičková, M., Pavlík, Z., Fiala, L., Černý, R., Thermal Conductivity of Mineral Wool Materials Partially Saturated by Water. International Journal of Thermophysics, 27(4), pp. 1214-1227. 2006.

[11] Pavlík, Z., Vejmelková, E., Fiala, L., Černý, R., Effect of Moisture on Thermal Conductivity of Lime-Based Composites. International Journal of Thermophysics, 30(6), pp. 1999-2014, 2009. 